\title{
Asymptomatic subjects with diabetes have a comparable risk of coronary artery disease to Non-diabetic subjects presenting chest pain: a 4-year community-based prospective study
}

\author{
Bo Kyung Koo ${ }^{1,2}$, Yun Gi Kim¹, Kyong Soo Park ${ }^{1}$ and Min Kyong Moon ${ }^{1,2^{*}}$
}

\begin{abstract}
Background: Although diabetes mellitus is an important risk factor of coronary artery disease (CAD), routine screening for CAD is not recommended for asymptomatic diabetic patients. We assessed the impact of chest pain on CAD risk according to the presence or absence of diabetes mellitus.

Methods: We investigated the future CAD event rate in subjects with and without chest pain according to the presence or absence of diabetes in a prospective large-scale community-based study in Korea.

Results: Among 8,574 subjects (4,032 men and 4,542 women) without a history of CAD, $0.8 \%$ and 2.2\% of nondiabetic and diabetic subjects, respectively, reported newly developed CAD events during 4 years of follow-up. Although the presence of chest pain at baseline was also significantly associated with an increased risk of CAD of more than 2-fold in both non-diabetic and diabetic subjects $(P<0.01)$, the risk of future CVD event in asymptomatic diabetic patients was not significantly different from that in non-diabetic subjects with chest pain (hazard ratio, 0.907; 95\% confidence interval, 0.412 - 1.998).

Conclusions: The CAD event rate of asymptomatic subjects with diabetes was comparable to that of non-diabetic subjects reporting chest pain. Considering the high risk of CAD in asymptomatic diabetic patients, more clinical trials aimed at formulating strategies to screen asymptomatic diabetic subjects should be carried out.
\end{abstract}

Keywords: Diabetes, Coronary artery disease, Chest pain

\section{Background}

A large population-based study has suggested that diabetes mellitus is a coronary artery disease (CAD) equivalent [1]. Therefore, it might be very valuable to be able to predict which patients with diabetes will have silent ischemia. However, recent studies have concluded that a conventional risk factor-based approach cannot identify high-risk patients in screening tests [2,3], and that there is no clinical benefit of routine screening of asymptomatic patients with diabetes [2,4]. Furthermore, since recent randomized controlled studies have shown

\footnotetext{
* Correspondence: mkmoon@snu.ac.kr

*Correspondence: mkmoon@snu.ac.kr
'Department of Internal Medicine, Seoul National University College of Medicine, 39 Boramae Road, Seoul, Dongjak-Gu 156-707, South Korea ${ }^{2}$ Department of Internal Medicine, Boramae Medical Center, Seoul, South Korea
}

that cardiac reperfusion therapy does not produce better clinical outcomes than medical therapy for stable CAD [5,6], these observations have raised the question of whether or not asymptomatic patients with diabetes should be screened for CAD and experts recommends that candidates for cardiac testing should be limited to those with (i) typical or atypical cardiac symptoms and (ii) an abnormal resting electrocardiogram (ECG) [7].

However, the prevalence of silent myocardial ischemia in asymptomatic diabetic patients with no cardiac history and with a normal 12-lead ECG at rest has been reported to be high $(\sim 35 \%)$ [8] and such asymptomatic diabetic patients suffer more future cardiac events than symptomatic patients do despite similar coronary atherosclerosis severity [9]. In the Detection of Ischemia in Asymptomatic Diabetics (DIAD) study, a large randomized clinical trial 
to show no clinical benefit of screening of asymptomatic patients with diabetes, only $15 \%$ of subjects classified as having moderate or large perfusion defects underwent coronary angiography within 120 days after screening [4], which might account for the lack of a significant difference between the screened and unscreened groups in that study.

Therefore, we investigated the future CAD event rate in diabetic patients with and without chest pain in a prospective community-based cohort study performed in the Korean population. In addition, we assessed the impact of chest pain on CAD risk according to the presence or absence of diabetes mellitus.

\section{Methods}

\section{Ansung-Ansan cohort design}

The Ansung and Ansan cohorts represent rural and urban areas of Korea, respectively. The design and baseline characteristics of these cohorts have been described elsewhere [10,11]. Briefly, the Ansung-Ansan cohort was established for a prospective large-scale communitybased epidemiologic study to investigate chronic diseases in Korea. The eligibility criteria were age 40-69 years old and residence within the borders of the survey areas for at least 6 months before testing. In Ansung, 5,018 of 7,192 eligible individuals were surveyed (70\% response rate) using a cluster sampling method stratified by age, sex, and residential district. Ansan is a representative urban community that had a population of 554,998 in 2000 [12]; 5,020 of 15,580 eligible subjects (32.4\%) were recruited for the survey through a random sampling method using the local telephone directory. The baseline survey was performed from 2000-2001, and biennial follow-up surveys have been performed since then. Throughout the study, data were collected by the same trained researchers and instruments. Anthropometric parameters and blood pressure were measured by standard methods. The fasting plasma concentrations of glucose, HbA1c, total cholesterol, triglycerides and HDL cholesterol were measured in a central laboratory as described previously $[10,11]$.

Participants completed questionnaires in face-to-face interviews about demographics and previous medical history, including myocardial infarction, heart failure, smoking, medication such as anti-hypertensive drugs or anti-diabetic drugs, and subjective symptoms such as chest pain and dyspnea.

This study was carried out in accordance with the Declaration of Helsinki (http://www.wma.net/en/30publications/10policies/b3/index.html). Informed written consent was obtained from all participants. The study protocol was approved by the ethics committee of the Korean Center for Disease Control and the Ajou University School of Medicine Institutional Review Board.

\section{Definitions}

Cases of diabetes mellitus were defined as subjects who used anti-diabetic medication including insulin at the time of the survey, had HbA1c $\geq 6.5 \%$ or 8-hour fasting plasma glucose $\geq 7.0 \mathrm{mmol} / \mathrm{L}$. Hypertension was defined as systolic blood pressure $\geq 140 \mathrm{mmHg}$, diastolic blood pressure $\geq 90 \mathrm{mmHg}$, or taking antihypertensive medications. Cases with systolic blood pressure $\geq 140 \mathrm{mmHg}$ or diastolic blood pressure $\geq 90 \mathrm{mmHg}$ were classified as "uncontrolled hypertension." Dyslipidemia was defined as triglycerides $\geq 1.7 \mathrm{mmol} / \mathrm{L}$ after at least 12 hours of fasting, LDL cholesterol $\geq 4.1 \mathrm{mmol} / \mathrm{L}$ according to NCEP criteria [13], or taking any lipid-lowering medications. ECG abnormalities suggesting myocardial ischemia at baseline included ST depression $\geq 1.0 \mathrm{~mm}, \mathrm{~T}$ wave inversion $\geq 5.0 \mathrm{~mm}$, ST elevation $\geq 1.0 \mathrm{~mm}$ or $\mathrm{Q}$ wave at any lead. The definition of a CAD event for next 4 years of follow-up was based on the questionnaire administered in biennial follow-up surveys. Subject with CAD events was defined as subject who answered that they took medication or underwent reperfusion therapy or bypass surgery for any CAD including myocardial infarction. A family history of CAD was defined as when a subject had at least one first-degree relative suffering from CAD. Information about the perception of chest pain according to activity intensity in daily life at baseline was also obtained from the questionnaire. The questionnaire on chest pain comprised questions about the presence of any type of chest pain in daily life, during mild-intensity activity such as walking, and moderate-intensity activity such as climbing stairs. The characteristics of chest pain at each activity level were further categorized as "heaviness," "tightness or squeezing," "burning," "stabbing," or "lancinating". Typical angina chest pain of CAD was defined by its characteristics, described as heaviness, tightness, or squeezing.

\section{Statistical analysis}

All data were analyzed by SPSS (SPSS Inc., Chicago, IL, USA). The results are presented as means \pm SD. We logarithmically transformed waist circumference, triglyceride concentration, HDL cholesterol concentration, $\mathrm{BMI}$, and urine albumin-to-creatinine ratio for analysis. To determine the significance of differences between baseline clinical characteristics in the development of $\mathrm{CAD}$ events during the follow-up period, linear regression and logistic regression analyses adjusted for age were used. In the case of categorical variable, general linear model was used. Cox regression analysis with dummy variables (to contrast the different categories) was used to analyze the hazard ratio (HR) of diabetes and chest pain at baseline for future CAD events adjusted for age, sex and BMI; non-diabetic subjects without chest pain were used as a reference risk group. Hazard function from Cox regression analysis adjusting 
sex and age were used to construct figures for CAD event according to chest pain and diabetes. The level of significance was set at $P<0.05$.

\section{Results}

Baseline characteristics

Of the 10,038 subjects in the Ansung-Ansan cohort, we included 8,574 subjects (4,032 men and 4,542 women) who had no history of ischemic heart disease and no ECG abnormality suggesting myocardial ischemia the present study. Among them, 1,203 (14\%) had diabetes mellitus at baseline. During a follow-up period of 4 years, $0.8 \%$ and $2.2 \%$ of non-diabetic and diabetic subjects, respectively, reported experiencing a newly developed CAD event (Table 1). Among 84 subjects with CAD events during follow-up period, 16 (7 in non-diabetic

Table 1 Baseline characteristics of subjects with or without coronary artery disease events over 4 years of follow-up

\begin{tabular}{|c|c|c|c|c|c|c|c|}
\hline & & \multicolumn{3}{|c|}{ Subjects without diabetes mellitus } & \multicolumn{3}{|c|}{ Subjects with diabetes mellitus } \\
\hline & & No CAD at follow-up & CAD at follow-up & $P^{a}$ & No CAD at follow-up & CAD at follow-up & $P^{a}$ \\
\hline \multicolumn{2}{|l|}{ N (\% Men) } & $7314(46.5)$ & $57(40.4)$ & 0.415 & $1176(50.9)$ & $27(48.1)$ & 0.994 \\
\hline \multicolumn{2}{|l|}{ Ansung (\% Men) } & $3289(43.7)$ & $36(36.1)$ & & $595(43.9)$ & $18(55.6)$ & \\
\hline \multicolumn{2}{|l|}{ Ansan (\% Men) } & $4025(48.7)$ & $21(47.6)$ & & $581(58.0)$ & $9(33.3)$ & \\
\hline \multicolumn{2}{|l|}{ Age (years) } & $51 \pm 9$ & $56 \pm 9$ & $<0.001$ & $56 \pm 9$ & $59 \pm 9$ & 0.050 \\
\hline \multicolumn{2}{|l|}{ BMI $\left(\mathrm{kg} / \mathrm{m}^{2}\right)$} & $24.4 \pm 3.1$ & $25.7 \pm 2.9$ & 0.001 & $25.6 \pm 3.3$ & $25.5 \pm 3.9$ & 0.988 \\
\hline \multirow[t]{2}{*}{ Waist circumference $(\mathrm{cm})$} & Men & $83.2 \pm 7.5$ & $86.5 \pm 6.7$ & 0.032 & $86.2 \pm 8.7$ & $88.5 \pm 8.8$ & 0.262 \\
\hline & Women & $80.6 \pm 9.5$ & $87.4 \pm 7.5$ & 0.001 & $87.1 \pm 8.6$ & $86.6 \pm 8.8$ & 0.699 \\
\hline \multicolumn{2}{|c|}{ Systolic blood pressure $(\mathrm{mmHg})$} & $116 \pm 18$ & $121 \pm 15$ & 0.249 & $124 \pm 19$ & $126 \pm 17$ & 0.986 \\
\hline \multicolumn{2}{|c|}{ Diastolic blood pressure $(\mathrm{mmHg})$} & $74 \pm 12$ & $76 \pm 9$ & 0.805 & $77 \pm 11$ & $76 \pm 10$ & 0.463 \\
\hline \multicolumn{2}{|l|}{$\mathrm{HbA1C}(\%)$} & $5.5 \pm 0.3$ & $5.6 \pm 0.4$ & 0.758 & $7.4 \pm 1.6$ & $7.1 \pm 1.5$ & 0.513 \\
\hline \multicolumn{2}{|l|}{ Fasting glucose $(\mathrm{mmol} / \mathrm{L})$} & $4.7 \pm 0.5$ & $4.7 \pm 0.4$ & 0.700 & $6.9 \pm 2.6$ & $6.7 \pm 2.5$ & 0.986 \\
\hline \multicolumn{2}{|l|}{ Total cholesterol (mmol/L) } & $4.93 \pm 0.90$ & $5.21 \pm 0.99$ & 0.031 & $5.21 \pm 1.07$ & $5.01 \pm 1.10$ & 0.402 \\
\hline \multirow[t]{2}{*}{ HDL cholesterol (mmol/L) } & Men & $1.16 \pm 0.27$ & $1.25 \pm 0.38$ & 0.327 & $1.11 \pm 0.26$ & $1.15 \pm 0.29$ & 0.630 \\
\hline & Women & $1.24 \pm 0.28$ & $1.22 \pm 0.31$ & 0.865 & $1.14 \pm 0.27$ & $1.17 \pm 0.23$ & 0.600 \\
\hline \multicolumn{2}{|l|}{ Triglyceride (mmol/L) } & $1.68 \pm 1.06$ & $1.95 \pm 0.99$ & 0.032 & $2.31 \pm 1.52$ & $2.07 \pm 0.96$ & 0.634 \\
\hline \multicolumn{2}{|l|}{ Serum creatinine $(\mu \mathrm{mol} / \mathrm{L})$} & $74 \pm 18$ & $72 \pm 14$ & 0.506 & $76 \pm 37$ & $80 \pm 28$ & 0.551 \\
\hline \multicolumn{2}{|c|}{ Urine microalbuminuria(mg/g Cr) } & $97 \pm 244$ & $79 \pm 60$ & 0.665 & $180 \pm 487$ & $182 \pm 191$ & 0.623 \\
\hline \multicolumn{2}{|c|}{ Normal (\%) } & 17.2 & 8.7 & & 10.6 & 0.0 & \\
\hline \multicolumn{2}{|l|}{ Microalbuminuria (\%) } & 79.3 & 91.3 & 0.424 & 79.4 & 80.0 & 0.475 \\
\hline \multicolumn{2}{|l|}{ Proteinuria (\%) } & 3.0 & 0.0 & & 10.0 & 20.0 & \\
\hline \multicolumn{8}{|l|}{ Smoker } \\
\hline \multicolumn{2}{|l|}{ Non-smoker (\%) } & 59.9 & 57.9 & & 56.2 & 53.3 & \\
\hline \multicolumn{2}{|l|}{ Ex-smoker (\%) } & 15.1 & 17.5 & 0.591 & 16.8 & 16.7 & 0.631 \\
\hline \multicolumn{2}{|l|}{ Smoker (\%) } & 25.0 & 24.6 & & 27.0 & 30.0 & \\
\hline \multicolumn{2}{|l|}{ Family history of CAD, N (\%) } & $22(0.3 \%)$ & $0(0)$ & 0.998 & $2(0.2)$ & $0(0)$ & 1.000 \\
\hline \multicolumn{2}{|l|}{ Hypertension, N (\%) } & $1355(18.5)$ & 19 (33.3) & 0.074 & $425(36.1)$ & $14(51.9)$ & 0.237 \\
\hline Antihypertensive drug, $\mathrm{N}$ & & $591(8.1)$ & $14(24.6)$ & $0.001^{c}$ & $260(22.1)$ & $11(40.7)$ & 0.090 \\
\hline Hypertension, uncontrolle & $N(\%)^{b}$ & $990(13.5)$ & $9(15.8)$ & 0.393 & $274(23.3)$ & $6(22.2)$ & 0.237 \\
\hline Dyslipidemia, N (\%) & & $3051(41.7)$ & $34(59.6)$ & $0.016^{\mathrm{d}}$ & $786(66.7)$ & $18(66.7)$ & 0.959 \\
\hline Cholesterol-lowering drug & N (\%) & $20(0.3)$ & 0 & 0.998 & $15(1.3)$ & 0 & 0.998 \\
\hline Triglyceride $\geq 1.7 \mathrm{mmol} / \mathrm{L}$, & $\sqrt{ }(\%)$ & $2627(35.9)$ & $31(54.4)$ & $0.009^{e}$ & $721(61.5)$ & $17(63.0)$ & 0.813 \\
\hline 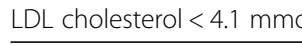 & /L, N (\%) & $6562(89.7)$ & $52(91.2)$ & 0.672 & $959(81.8)$ & $22(81.5)$ & 0.887 \\
\hline LDL cholesterol $<3.3 \mathrm{mmc}$ & L, N (\%) & $4860(66.5)$ & $38(66.7)$ & 0.870 & $672(57.3)$ & $18(66.7)$ & 0.379 \\
\hline 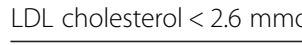 & /L, N (\%) & $2212(30.2)$ & $17(29.8)$ & 0.967 & $306(26.1)$ & $11(40.7)$ & 0.116 \\
\hline $\mathrm{HbA1c}<7 \%, \mathrm{~N}(\%)$ & & - & - & - & $609(51.8)$ & $16(59.3)$ & 0.423 \\
\hline Living in urban area (Ansa & ) (\%) & $51.4 \%$ & $33.3 \%$ & 0.150 & $46.5 \%$ & $30.0 \%$ & 0.622 \\
\hline
\end{tabular}

Abbreviations: CAD, coronary artery disease.

${ }^{\mathrm{a}}$ Age-adjusted $P$ value; ${ }^{\mathrm{b}}$ Cases with systolic blood pressure $\geq 140 \mathrm{mmHg}$ or diastolic blood pressure $\geq 90 \mathrm{mmHg}$ irrespective of medication; ${ }^{\mathrm{C}}$ Odds ratio (OR) for $\mathrm{CAD}=2.829[1.501-5.333] ;{ }^{\mathrm{d}} \mathrm{OR}=1.928[1.132-3.285] ;{ }^{\mathrm{e}} \mathrm{OR}=2.014[1.192-3.404]$. 
subjects and 9 in diabetic subjects) reported to have undergone reperfusion therapy in that period. The presence of diabetes at baseline independently increased the risk of future CAD risk (age-, sex-, and BMIadjusted odds ratio $[\mathrm{OR}]=2.083$ [95\% confidence interval, 1.290 - 3.365], $P=0.003)$. The baseline characteristics according to development of CAD events during the follow-up period are shown in Table 1. Among nondiabetic subjects, those who developed CAD were significantly older $(P<0.001)$, had higher BMI $(P=0.001)$ and waist circumference (WC) $(P=0.032$ in men and 0.001 in women), and had hypertriglyceridemia more frequently at baseline $(P=0.009)$. However, in diabetic subjects, there were no significant differences between subjects with and without CAD with respect to baseline characteristics, except age $(P=0.050)$. The proportions of all diabetes patients who attained the clinical goals were as follows: $52.0 \%$ for $\mathrm{HbA} 1 \mathrm{c}<7 \%, 26.4 \%$ for $\mathrm{LDL}<2.6 \mathrm{mmol} / \mathrm{L}$, and $76.7 \%$ for blood pressure $<140 / 90 \mathrm{mmHg}$; none of these parameters differed significantly between those with and without CAD events (Table 1). Age was only a significant risk factor of future CAD events in both men and women in the case of diabetes (data not shown).

\section{CAD event rate according to the presence or absence of chest pain}

At baseline, $22.8 \%$ and $19.6 \%$ of non-diabetic and diabetic subjects, respectively, reported having any type of chest pain in daily life. Approximately $40 \%$ of subjects with CAD events previously reported chest pain at baseline irrespective of glycemic status. Among all subjects reporting chest pain at baseline, $1.6 \%$ and $5.1 \%$ of nondiabetic and diabetic subjects, respectively, experienced CAD events over the next 4 years. The presence of chest pain at baseline was significantly associated with a 2 -fold increase in future CAD risk in both non-diabetic $(\mathrm{HR}=$ 2.879 [1.536 - 5.394], $P=0.001)$ and diabetic subjects $(\mathrm{OR}=3.489 \quad[1.620-7.512], \quad P=0.001)$ even after adjusting for sex and age (Table 2). Exertional chest pain during mild-degree exercise was also a significant predictive factor of CAD events in non-diabetic subjects (Table 2). In contrast, there was no significant association between chest pain during mild-degree exercise and the CAD event rate in diabetic subjects.

Next, we estimated HR of CAD events according to presence or absence of chest pain in the subjects with or without diabetes using Cox proportional hazards model. All study subjects were categorized into 4 groups: nondiabetic subjects without chest pain at baseline (Group 1), non-diabetic subjects with chest pain (Group 2), diabetic subjects without chest pain (Group 3), and diabetic subjects with chest pain (Group 4). Group 4 had the worst prognosis, whereas Group 1 had the best (Figure 1). Groups 2 and 3 had intermediate event rates as well as similar outcomes. Table 3 presents the results of the Cox proportional hazards model comparing the subjects in Groups 2-4 with those in Group 1. Groups 2-4 had significantly higher HRs than Group 1 even after adjusting for age, sex, and other risk factor of CAD. Next, we compared only Groups 2 and 3. The age- and sexadjusted HR of Group 3 was not significantly different from that of Group 2 ( $\mathrm{HR}=0.907$ [0.412 - 1.998], $P=0.809$ ), suggesting these groups have similar CAD event rates.

\section{Discussion}

In our study, among 8,574 subjects without a history of CAD, $0.8 \%$ and $2.2 \%$ of non-diabetic and diabetic

Table 2 Hazard ratios (HR) of CAD events during next 4 years according to the perception of chest pain at baseline

\begin{tabular}{|c|c|c|c|c|c|c|c|c|}
\hline & \multicolumn{4}{|c|}{ Subjects without diabetes mellitus } & \multicolumn{4}{|c|}{ Subjects with diabetes mellitus } \\
\hline & $\begin{array}{l}\text { Number } \\
\text { of cases }\end{array}$ & $\begin{array}{l}\text { CAD at follow-up } \\
\text { (1000 person-yr) }\end{array}$ & Hazard ratios $^{a}$ & $P^{\mathrm{b}}$ & $\begin{array}{l}\text { Number } \\
\text { of cases }\end{array}$ & $\begin{array}{l}\text { CAD at follow-up } \\
\text { (1000 person-yr) }\end{array}$ & Hazard ratios $^{a}$ & $P^{\mathrm{b}}$ \\
\hline \multicolumn{9}{|c|}{ Chest pain, total (\%) } \\
\hline Absence & 5624 & 1.0 & 2.879 & \multirow{2}{*}{-0.001} & 959 & 3.9 & 3.489 & \multirow{2}{*}{-0.00} \\
\hline Presence & 1674 & 2.7 & $(1.536-5.394)$ & & 235 & 13.0 & $(1.620-7.512)$ & \\
\hline \multicolumn{9}{|c|}{ Typical chest pain (\%) ${ }^{c}$} \\
\hline Absence & 6596 & 1.1 & 2.814 & \multirow{2}{*}{-0.005} & 1084 & 4.6 & 3.279 & \multirow{2}{*}{-0.007} \\
\hline Presence & 779 & 3.2 & $(1.370-5.780)$ & & 120 & 15.0 & $(1.380-7.793)$ & \\
\hline \multicolumn{9}{|c|}{ Chest pain on mild-intensity activity (\%) ${ }^{\mathrm{d}}$} \\
\hline Absence & 7146 & 1.2 & 6.110 & \multirow{2}{*}{-0.003} & 1171 & 5.6 & 1.904 & \multirow{2}{*}{-0.530} \\
\hline Presence & 94 & 8.2 & $(1.861-20.054)$ & & 19 & 13.3 & $(0.255-14.222)$ & \\
\hline \multicolumn{9}{|c|}{ Chest pain on moderate-intensity exercise (\%) ${ }^{d}$} \\
\hline Absence & 7067 & 1.3 & 2.017 & \multirow{2}{*}{0.338} & 1158 & 5.2 & 3.926 & \multirow[b]{2}{*}{-0.028} \\
\hline Presence & 192 & 2.7 & $(0.480-8.472)$ & & 33 & 23.8 & $(1.162-13.265)$ & \\
\hline
\end{tabular}

Abbreviations: CAD, coronary artery disease.

${ }^{a}$ Hazard ratio of chest pain for CAD events over the next 4 years adjusting sex and age; ${ }^{b}$ sex- and age- adjusted $P$ value; ${ }^{c}$ chest pain described as heaviness, tightness, or squeezing regardless of activity level or chest pain perception; ${ }^{d}$ any chest pain associated with activity. 


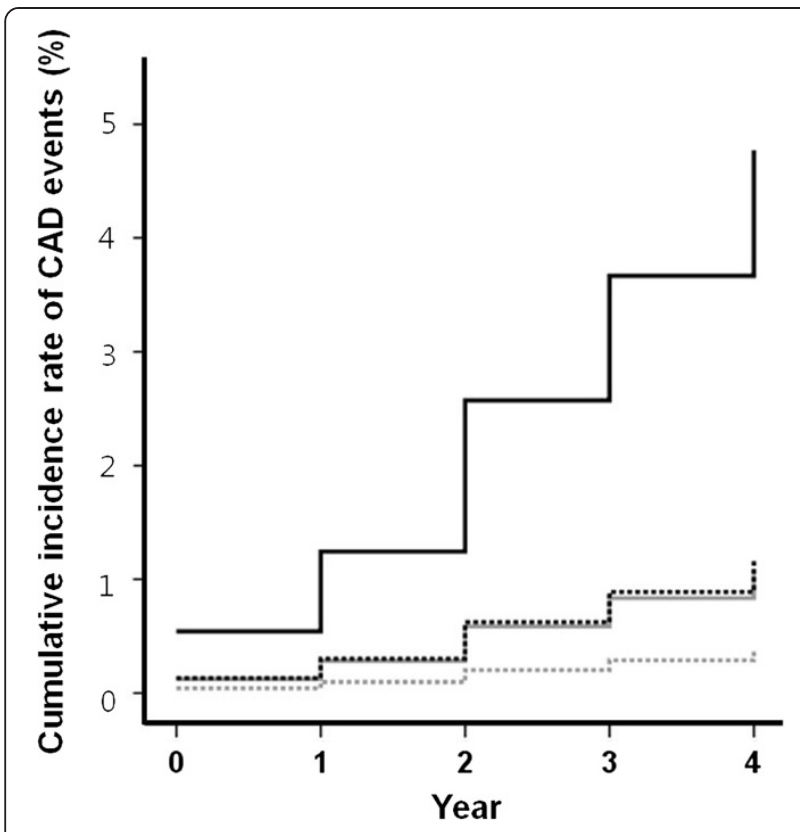

Figure 1 Cox proportional hazards model for the probability of coronary artery disease (CAD) events over the 4 years. Cox proportional hazards model for the probability of CAD events in 1,203 subjects with diabetes mellitus and 7,371 non-diabetic subjects with and without chest pain at baseline. Gray dotted line, nondiabetic subjects without chest pain (Group 1); gray solid line, nondiabetic subjects with chest pain (Group 2); black dotted line, diabetic subjects without chest pain (Group 3); black solid line, diabetic subjects with chest pain (Group 4).

subjects, respectively, reported experiencing newly developed CAD events during a 4-year follow-up period; these rates are concordant with those of the DIAD study [4]. Our results corroborate those of earlier reports indicating that subjects with diabetes mellitus have an increased incidence of cardiovascular events $[1,14]$ and show that the presence of chest pain at baseline is significantly associated with an increase in future CAD risk of more than 2-fold in both non-diabetic and diabetic subjects.
Interestingly, diabetic subjects without chest pain had a similar CAD event rate to non-diabetic subjects with chest pain, implying that the results of clinical trials conducted in asymptomatic non-diabetic subjects are not applicable to asymptomatic diabetic subjects. The well-known clinical trials which showed that revascularization was not superior to medical treatment for stable CAD $[6,15]$ included subjects with diabetes only $20-35 \%$ of the study population and those results should be carefully interpreted when applying them to diabetic subjects.

Although the Bypass Angioplasty Revascularization Investigation 2 Diabetes (BARI 2D) trial did not find any difference in cardiac outcomes between revascularization and medical treatment in the patients with diabetes, subgroup analysis showed that the prognosis of severe CAD lesions was better with revascularization treatment [5]. The survival of diabetic patients with silent ischemia is known to be related to the severity of CAD [16]. Considering the fact that small proportion of subjects with moderate or large perfusion defects underwent coronary angiography within 120 days after screening in the DIAD study [4], the benefit of screening might be underestimated in that study.

The present study also revealed that no baseline characteristics, except age in diabetic subjects, were significantly different between subjects with and without CAD, which corroborates the results of previous studies $[2,3]$. In contrast, the traditional risk factors for CAD such as age, obesity, and hypertension were significantly associated with future CAD event rates in non-diabetic subjects. Previous studies report that CAD risk indicators other than traditional risk factors for asymptomatic diabetic patients include autonomic neuropathy $[2,17]$, retinopathy [18,19], and renal complications [20,21]. However, in the present study, we only had information on kidney function, and there was no difference in serum creatinine level or albumin excretion ratio with respect to $C A D$ events in diabetic patients.

Table 3 Hazard ratios (HR) of incident CAD events over 4 years of follow-up

\begin{tabular}{|c|c|c|c|c|c|c|}
\hline & \multicolumn{2}{|c|}{ Model 1} & \multicolumn{2}{|c|}{ Model 2} & \multicolumn{2}{|c|}{ Model 3} \\
\hline & HR & $P$ & HR & $P$ & HR & $P$ \\
\hline Non-diabetic subjects without chest pain (Group 1) & 1 & & 1 & & 1 & \\
\hline \multirow[t]{2}{*}{ Non-diabetic subjects with chest pain (Group 2) } & 2.768 & \multirow{2}{*}{$-<0.001$} & 2.892 & \multirow{2}{*}{-0.001} & 2.782 & \multirow{2}{*}{-0.002} \\
\hline & $(1.485-5.160)$ & & $(1.546-5.408)$ & & $(1.486-5.208)$ & \\
\hline \multirow[t]{2}{*}{ Diabetic subjects without chest pain (Group 3) } & 4.008 & \multirow{2}{*}{$<0.001$} & 3.253 & \multirow{2}{*}{-0.001} & 2.626 & \multirow{2}{*}{-0.005} \\
\hline & $(2.079-7.727)$ & & $(1.671-6.334)$ & & $(1.333-5.172)$ & \\
\hline \multirow[t]{2}{*}{ Diabetic subjects with chest pain (Group 4) } & 13.220 & \multirow{2}{*}{$-<0.001$} & 11.241 & \multirow{2}{*}{$-<0.001$} & 8.539 & \multirow{2}{*}{$-<0.00$} \\
\hline & $(6.543-26.712)$ & & $(5.522-22.881)$ & & $(4.118-17.705)$ & \\
\hline
\end{tabular}

Abbreviations: CAD, coronary artery disease.

Model 1: No adjusting.

Model 2: Adjusted for age and sex.

Model 3: Adjusted for age, sex, bmi, hypertension, dyslipidemia, smoking history and family history of CAD. 
Improvements in the management of diabetic patients with multiple risk factors might be a reason for the lack of associations between metabolic risk factors and the development of CAD events. In the present study, $23.2 \%$ of diabetic patients had uncontrolled hypertension at baseline, which is somewhat lower than the $33 \%$ reported in the general population in the Korean National Health and Nutrition Examination Survey in 2001 [22] and the 31\% reported in the DIAD study population [2]. Intensive intervention with multiple drug combinations produces sustained beneficial effects with respect to vascular complications and mortality rates from any cause and cardiovascular causes, respectively [23]. A recent US report demonstrated that the mortality rates among both American men and women with diabetes decreased substantially between 1997 and 2006, reducing the absolute difference between adults with and without diabetes [24].

However, further study to determine the high-risk population among asymptomatic diabetic patients is warranted by the fact that diabetic patients with silent ischemia have poor outcomes [25] and that the prognosis of severe CAD lesions is better with revascularization treatment [5]. Asymptomatic diabetic patients with a higher coronary disease burden suffer more future cardiac events than asymptomatic patients do [26,27].

The main limitation of our study is that CAD events were determined from questionnaires without objective confirmatory data. The presence or absence of chest pain was also determined from questionnaires, which might result in underestimation. The relatively short follow-up duration of the present study is also a limitation for investigating the CAD event rate. However, the prospective 4-year follow-up of a large communitybased cohort means our results are stronger than those of other studies are. Furthermore, few studies have compared the impacts of chest pain on future CAD in those with and without diabetes.

\section{Conclusions}

The CAD event rate of asymptomatic subjects with diabetes was comparable to that of non-diabetic subjects reporting chest pain. Considering the high risk of CAD in asymptomatic diabetic patients and morbidity and mortality due to CAD, more clinical trials aimed at formulating strategies to screen asymptomatic diabetic subjects should be carried out.

\section{Competing interests}

We have no potential conflicts of interest to report.

\section{Authors' contributions}

BK wrote the manuscript and collected data. YK made substantial contributions to conception and design and KP contributed to the discussion and reviewed the manuscript. MM contributed to the discussion, and reviewed and edited the manuscript. All authors read and approved the final manuscript.

\section{Acknowledgements}

This work has no grant support. The data of this study was provided by the National Genome Research Institute, Korean Center for Disease Control and Prevention.

Received: 23 January 2013 Accepted: 15 October 2013 Published: 18 October 2013

\section{References}

1. Haffner SM, Lehto S, Ronnemaa T, Pyorala K, Laakso M: Mortality from coronary heart disease in subjects with type 2 diabetes and in nondiabetic subjects with and without prior myocardial infarction. N Engl J Med 1998, 339:229-234.

2. Wackers FJ, Young LH, Inzucchi SE, Chyun DA, Davey JA, Barrett EJ, Taillefer R, Wittlin SD, Heller GV, Filipchuk N, et al: Detection of silent myocardial ischemia in asymptomatic diabetic subjects: the DIAD study. Diabetes Care 2004, 27:1954-1961.

3. Scognamiglio R, Negut C, Ramondo A, Tiengo A, Avogaro A: Detection of coronary artery disease in asymptomatic patients with type 2 diabetes mellitus. J Am Coll Cardiol 2006, 47:65-71.

4. Young $L H$, Wackers FJ, Chyun DA, Davey JA, Barrett EJ, Taillefer R, Heller GV, Iskandrian AE, Wittlin SD, Filipchuk N, et al: Cardiac outcomes after screening for asymptomatic coronary artery disease in patients with type 2 diabetes: the DIAD study: a randomized controlled trial. Jama 2009, 301:1547-1555.

5. Frye RL, August P, Brooks MM, Hardison RM, Kelsey SF, MacGregor JM, Orchard TJ, Chaitman BR, Genuth SM, Goldberg SH, et al: A randomized trial of therapies for type 2 diabetes and coronary artery disease. $N$ Engl $J$ Med 2009, 360:2503-2515.

6. Boden WE, O'Rourke RA, Teo KK, Hartigan PM, Maron DJ, Kostuk WJ, Knudtson M, Dada M, Casperson P, Harris CL, et al: Optimal medical therapy with or without $\mathrm{PCl}$ for stable coronary disease. N Engl J Med 2007, 356:1503-1516.

7. American Diabetes Association: Standards of medical care in diabetes2012. Diabetes Care 2012, 35(Suppl 1):S11-S63.

8. Valensi P, Paries J, Brulport-Cerisier V, Torremocha F, Sachs RN, Vanzetto G, Cosson E, Lormeau B, Attali JR, Marechaud R, et al: Predictive value of silent myocardial ischemia for cardiac events in diabetic patients: influence of age in a French multicenter study. Diabetes Care 2005, 28:2722-2727.

9. Choi EK, Koo BK, Kim HS, Cho YM, Kang HJ, Cho YS, Chung WY, Chae H, Choi DJ, Oh BH, et al: Prognostic significance of asymptomatic coronary artery disease in patients with diabetes and need for early revascularization therapy. Diabet Med 2007, 24:1003-1011.

10. Cho NH, Jang HC, Choi SH, Kim HR, Lee HK, Chan JC, Lim S: Abnormal liver function test predicts type 2 diabetes: a community-based prospective study. Diabetes Care 2007, 30:2566-2568.

11. Choi SH, Kim TH, Lim S, Park KS, Jang HC, Cho NH: Hemoglobin A1c as a diagnostic tool for diabetes screening and new-onset diabetes prediction: a 6-year community-based prospective study. Diabetes Care 2011, 34:944-949.

12. Statistics Korea: Population census. In Book Population Census. City: Daejeon; 2000.

13. Grundy SM, Cleeman JI, Daniels SR, Donato KA, Eckel RH, Franklin BA, Gordon DJ, Krauss RM, Savage PJ, Smith SC Jr, et al: Diagnosis and management of the metabolic syndrome: an American Heart Association/National Heart, Lung, and Blood Institute Scientific Statement. Circulation 2005, 112:2735-2752.

14. Stamler J, Vaccaro O, Neaton JD, Wentworth D: Diabetes, other risk factors, and 12-yr cardiovascular mortality for men screened in the Multiple Risk Factor Intervention Trial. Diabetes Care 1993, 16:434-444.

15. Pfisterer M: Long-term outcome in elderly patients with chronic angina managed invasively versus by optimized medical therapy: four-year follow-up of the randomized Trial of Invasive versus Medical therapy in Elderly patients (TIME). Circulation 2004, 110:1213-1218.

16. Weiner DA, Ryan TJ, Parsons L, Fisher LD, Chaitman BR, Sheffield LT, Tristani FE: Significance of silent myocardial ischemia during exercise testing in patients with diabetes mellitus: a report from the Coronary Artery Surgery Study (CASS) Registry. Am J Cardiol 1991, 68:729-734.

17. Vinik Al, Maser RE, Mitchell BD, Freeman R: Diabetic autonomic neuropathy. Diabetes Care 2003, 26:1553-1579. 
18. Klein BE, Klein R, McBride PE, Cruickshanks KJ, Palta M, Knudtson MD, Moss SE, Reinke JO: Cardiovascular disease, mortality, and retinal microvascular characteristics in type 1 diabetes: Wisconsin epidemiologic study of diabetic retinopathy. Arch Intern Med 2004, 164:1917-1924.

19. Hiller R, Sperduto RD, Podgor MJ, Ferris FL 3rd, Wilson PW: Diabetic retinopathy and cardiovascular disease in type II diabetics. The Framingham Heart Study and the Framingham Eye Study. Am J Epidemiol 1988, 128:402-409.

20. Mann JF, Gerstein HC, Pogue J, Bosch J, Yusuf S: Renal insufficiency as a predictor of cardiovascular outcomes and the impact of ramipril: the HOPE randomized trial. Ann Intern Med 2001, 134:629-636.

21. Doobay AV, Anand SS: Sensitivity and specificity of the ankle-brachial index to predict future cardiovascular outcomes: a systematic review. Arterioscler Thromb Vasc Biol 2005, 25:1463-1469.

22. The Korean Ministry of Health and Welfare: Report of The Korean Nationa Health and Nutrition Examination Survey 2001. In Book Report of The Korean National Health and Nutrition Examination Survey 2001. City: Seoul; 2003.

23. Gaede P, Lund-Andersen H, Parving HH, Pedersen O: Effect of a multifactorial intervention on mortality in type 2 diabetes. $N$ Eng/ $\mathrm{J}$ Med 2008, 358:580-591.

24. Gregg EW, Cheng YJ, Saydah S, Cowie C, Garfield S, Geiss L, Barker L: Trends in death rates among U.S. adults with and without diabetes between 1997 and 2006: findings from the National Health Interview Survey. Diabetes Care 2012, 35:1252-1257.

25. Choi EK, Chun EJ, Choi SI, Chang SA, Choi SH, Lim S, Rivera JJ, Nasir K, Blumenthal RS, Jang $\mathrm{HC}$, Chang $\mathrm{HJ}$ : Assessment of subclinical coronary atherosclerosis in asymptomatic patients with type 2 diabetes mellitus with single photon emission computed tomography and coronary computed tomography angiography. Am J Cardiol 2009, 104:890-896.

26. Hadamitzky M, Hein F, Meyer T, Bischoff B, Martinoff S, Schomig A, Hausleiter J: Prognostic value of coronary computed tomographic angiography in diabetic patients without known coronary artery disease. Diabetes Care 2010, 33:1358-1363.

27. Elkeles RS, Godsland IF, Feher MD, Rubens MB, Roughton M, Nugara F, Humphries SE, Richmond W, Flather MD: Coronary calcium measurement improves prediction of cardiovascular events in asymptomatic patients with type 2 diabetes: the PREDICT study. Eur Heart J 2008, 29:2244-2251.

doi:10.1186/1471-2261-13-87

Cite this article as: Koo et al:: Asymptomatic subjects with diabetes have a comparable risk of coronary artery disease to Non-diabetic subjects presenting chest pain: a 4-year community-based prospective study. BMC Cardiovascular Disorders 2013 13:87.

\section{Submit your next manuscript to BioMed Central and take full advantage of:}

- Convenient online submission

- Thorough peer review

- No space constraints or color figure charges

- Immediate publication on acceptance

- Inclusion in PubMed, CAS, Scopus and Google Scholar

- Research which is freely available for redistribution

Submit your manuscript at www.biomedcentral.com/submit
Biomed Central 